\title{
REVIEW \\ Methane and Hydrogen Storage in Metal Organic Frameworks: A Mini Review
}

\author{
Oghenegare Emmanuel Eyankware ${ }^{*} \quad$ Idaeresoari Harriet Ateke $^{2}$ \\ 1. TegaFej Consulting Services, Port Harcourt, Rivers State, Nigeria \\ 2. Department of Petroleum and Gas Engineering, University of Port Harcourt, Rivers state, Nigeria
}

\section{ARTICLE INFO}

Article history

Received: 30 November 2020

Accepted: 9 December 2020

Published Online: 30 December 2020

\section{Keywords:}

Methane

Hydrogen

Metal organic framework

Adsorption

Storage

Computational

\section{ABSTRACT}

The need for a net zero carbon emission future is imperative for environmental sustainability hence, intensive carbon fuels would need to be replaced with less carbon emitting energy sources such as natural gas till clean energy source such as hydrogen becomes commercialized. As a result, this mini review discusses the use of metal organic framework (MOF) for adsorption of methane and hydrogen in specially designed tanks for improved performance so as to increase their applicability. Herein, adsorption (delivery) capacity of selected high performing MOFs for methane and hydrogen storage were highlighted in reference to the targets set by United States Department of Energy's Advanced Research Projects Agency-Energy (ARPA-E) and Fuel Cells Technology Office. In this regard, specific design and chemistry of MOFs for improved methane and hydrogen adsorption were highlighted accordingly. In addition, an overview of computational and molecular studies of hypothetical MOFs was done - the various approaches used and their proficiency for construction of specific of crystalline structures and topologies were herewith discussed.

oil for energy generation to drive their respective economic activities. This challenge posed to environmental sustainability in the form of extreme weather events such as drought, increasing sea levels and deforestation etc. that threaten human development and existence therefore necessitates the need to investigate and deploy less carbon emitting carbon energy sources such as natural gas or better still deploy clean energy sources such as hydrogen that would have limit $\mathrm{CO}_{2}$ emissions and facilitate achievement of net zero carbon future via cleaner energy sources - natural gas combustion emits $49 \%$ and $25 \%$ less $\mathrm{CO}_{2}$ than coal (anthracite) and crude oil (gasoline) respectively (unit of measurement is pound $\mathrm{CO}_{2}$ per million Btu of

*Corresponding Author:

Oghenegare Emmanuel Eyankware,

TegaFej Consulting Services, Port Harcourt, Rivers State, Nigeria;

Email:tegafej@gmail.com 
energy produced) while combustion of hydrogen does not produce $\mathrm{CO}_{2}$ as a by-product (cleanest energy source).

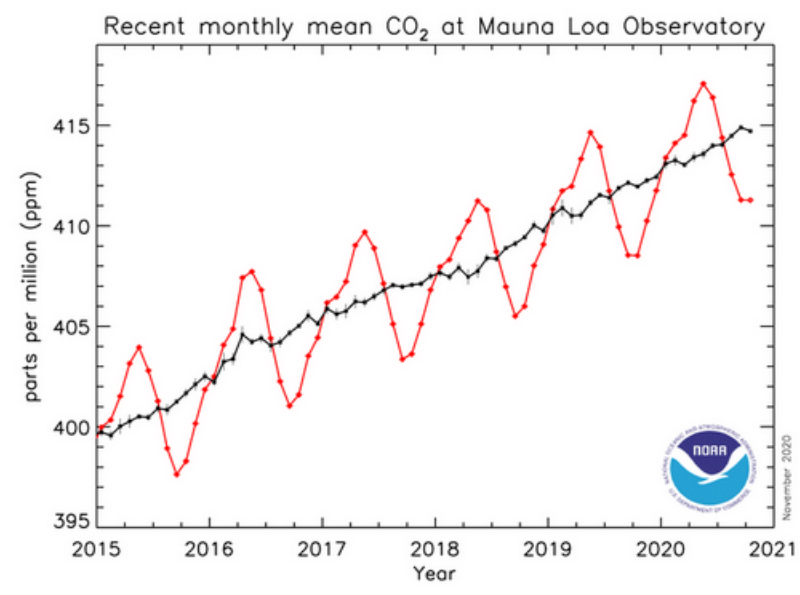

Figure 1. Trends in Atmospheric $\mathrm{CO}_{2}$ concentration - ${ }^{[4]}$ red line shows values for monthly averages while black line represent mean monthly values after correcting for monthly seasonal cycle, reproduced from ${ }^{[3]}$

In other words, natural gas can be considered as a bridging fuel that can facilitate transformation of the world's energy mix to one that is clean energy dominated by hydrogen. Due to the fact that natural gas is made up of over $90 \%$ composed of methane $(\mathrm{CH} 4)^{[5]}$, its combustion releases less carbon as well via Equation 1; this highlights its propensity to replace "dirty" fossil fuels in this phase of global energy transition. Corroborating this, Müller et al. highlighted in their work that NG offers advantages such as low fuel costs due to a higher energy content when compared to gasoline, reduced carbon emission as earlier highlighted and lower release of air pollutants (reduces NOx emissions) ${ }^{[6]}$ and a high Research Octane Number (RON=107) as compared to other fossil fuels ${ }^{[7]}$. On the other hand, hydrogen which is the cleanest energy source whose combustion products is only heat and water as shown in Equation 2 is a reliable energy source that can totally eliminate the emission of GHGs into the atmosphere and fast track achievement of net zero carbon emission future for environmental sustainability. In this regard, hydrogen has also been reported to be an efficient source for energy production; Suh et al. reported that hydrogen's energy content is three times $(123 \mathrm{MJ} / \mathrm{kg})$ more than that of gasoline $(47.2 \mathrm{MJ} / \mathrm{kg})^{[8]}$ although the situation is reversed in volumetric capacity as hydrogen possesses 8.4 MJ/L while gasoline possesses $32 \mathrm{MJ} / \mathrm{L}^{[9]}$. Considering these merits, hydrogen becomes a go-to energy source that would facilitate energy transition to carbon free future.

$\mathrm{CH}_{4}+2 \mathrm{O}_{2} \rightarrow \mathrm{CO}_{2}+2 \mathrm{H}_{2} \mathrm{O}+$ Energy $(890 \mathrm{KJ} / \mathrm{g})$

$\mathrm{H}_{2}+1 / 2 \mathrm{O}_{2} \rightarrow \mathrm{H}_{2} \mathrm{O}+$ Energy $(286 \mathrm{KJ} / \mathrm{g})$
In order to use these less carbon emitting fuels for practical and industrial applications, they have to be stored in carriage systems, preferably high pressure storage vessels; this becomes even more important as these energy sources exist in gaseous phase at atmospheric conditions (low pressures and ambient temperatures) with high entropy and system disorderliness; unfortunately, herein lays the drawbacks of using these energy sources for commercial applications. The difficulty in storing these gases and the limited amount that can be stored in carriage systems for a certain period of time limits their applicability. For example, it is reported that $5-13 \mathrm{~kg}$ of hydrogen needs to be stored for an automobile to drive a distance of 300 miles ${ }^{[8]}$; same applies to natural gas storage in carriage systems which conclusively highlights that carriage systems need to be refilled often, limiting their applicability. In addition, high pressure gas storage systems that are costly would be needed to store these gases on vehicles and process systems for commercial and industrial applications.

Therefore, prevailing technologies for storing these gases operate at high pressures - methane is currently being stored at high pressures of 250 bar [for compressed natural gas $(\mathrm{CNG})$, will be discussed in later section] while hydrogen is stored at high pressures of $700 \mathrm{bar}$, highlighting the need to design special storage tanks, high cost of storage ${ }^{[10]}$ and possible safety concerns that arise due to these factors highlighted. Considering these prevailing drawbacks, there is need to design advanced technologies such as compressed natural gas (CNG), liquefied natural gas (LNG), natural gas hydrates (NGH) and adsorbed natural gas (ANG) for NG storage and compressed gaseous storage, liquid storage and solid-state storage for hydrogen storage that would store gases at low pressures at ambient conditions while exhibiting high storage capacity that is critical to increase the propensity of deploying natural gas and hydrogen for commercial and industrial applications.

This has necessitated intense research into these highlighted advanced technologies and storage mechanism that can store these gases at low pressures and ambient temperatures where applicable. As a result, this review seeks to evaluate the most promising of these advanced storage technologies for methane and hydrogen storage with focus on ANG due to its promising properties. Herein, an advanced and porous adsorbent, metal organic framework was would be discussed with focus on highlighting its outstanding properties for methane storage would be discussed in view of highlighting advances that have been recorded in recent years. 


\section{Methane and Hydrogen Storage}

In this section, different existing technologies and storage mechanisms used for methane and hydrogen storage would be highlighted. Particular attention would be paid to their characteristics that make them suitable or not suitable for commercial and industrial applications. Finally, the most suitable of these technologies would be highlighted for further discussion.

\subsection{Mechanisms for Methane Storage}

Currently, there are established and popular technologies for storage of methane - these include LNG and CNG. Also, there are other mechanisms of methane storage such as $\mathrm{NGH}$ and $\mathrm{ANG}$ that are active areas which seeks to ameliorate the drawbacks of the popular storage technologies for process and energy methane storage. These different mechanisms will be discussed as follows;

Different methods have been proposed and used for natural gas storage. Chen et al. itemized them ${ }^{[7]}$ as;

(1) Liquefied Natural Gas (LNG)

(2) Compressed Natural Gas (CNG)

(3) Natural Gas Hydrates (NGH)

(4) Adsorbed Natural Gas (ANG)

\subsubsection{Liquefied Natural Gas (LNG)}

LNG is a form of natural gas that exists at cryogenic conditions of $-161^{\circ} \mathrm{C}$ and $\sim 1$ bar - it is 600 times denser than natural gas in its gaseous phase hence; it outperforms natural gas in terms of efficiency of storage and transportation across long distances in the absence of pipeline networks. Also, its volumetric energy density is higher than $\mathrm{CNG}$ at 22.2 $\mathrm{MJ} / \mathrm{L}(-161 \mathrm{oC}$ and $0.9 \mathrm{bar})$ as against 9.06 $\mathrm{MJ} / \mathrm{L}$ (250 bar). Due to its efficacy for long distance transportation, different processes and cascades that facilitate an LNG value chain have been developed and patented for natural gas liquefaction; a popular liquefaction process known as mixed propane refrigerant liquefaction process is shown in Figure 2. As highlighted in the liquefaction process below, a typical process involves basic processes such as pre-treatment of natural gas, acid gas removal, dehydration, removal of impurities such as mercury and other trace elements and liquefaction process using different process loops with cryogenics for purposes of heat exchange.

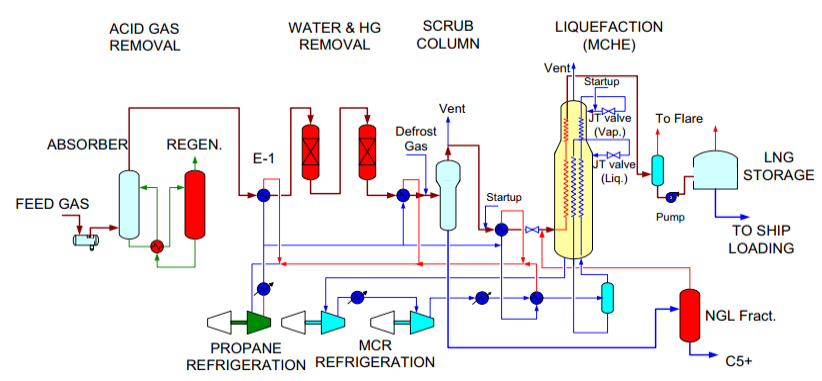

Figure 2. C3-MR liquefaction process, reproduced from ${ }^{[11]}$

Despite the suitability of LNG for long distance transportation of methane, the cryogenic conditions at which it must be stored necessitating the use of special membrane tanks limits its usage in conventional process systems. In addition, the high cost of installation of baseload LNG liquefaction plants in correspondence to their energy intensive processes results to high cost of operations ${ }^{[12]}$ which consequently hinders the rapid commercial and industrial applicability of LNG. Hence, it becomes difficult to use LNG in high carbon emitting sectors such transportation and other conventional process systems obtainable in petrochemical industries.

\subsubsection{Compressed Natural Gas (CNG)}

Currently being used as an energy source in vehicles (deployed in Benin City, Nigeria), CNG has shown promising properties such as eco-friendliness, low cost of storage as compared to LNG, wide range of applicability and compatibility for spark and compression ignition engines ${ }^{[13]}$ to prompt its commercial deployment. Its suitability as a means of storing methane is evident in the fact its volume is $<1 \%$ of the volume of methane at standard atmospheric conditions due to its high pressure storage conditions (typical conditions of storing CNG ranges from 200 - 248 bar). Due to the merits of CNG for commercial usage, well developed processes have been patented for $\mathrm{CNG}$ production; one of such processes is shown in Figure 3.

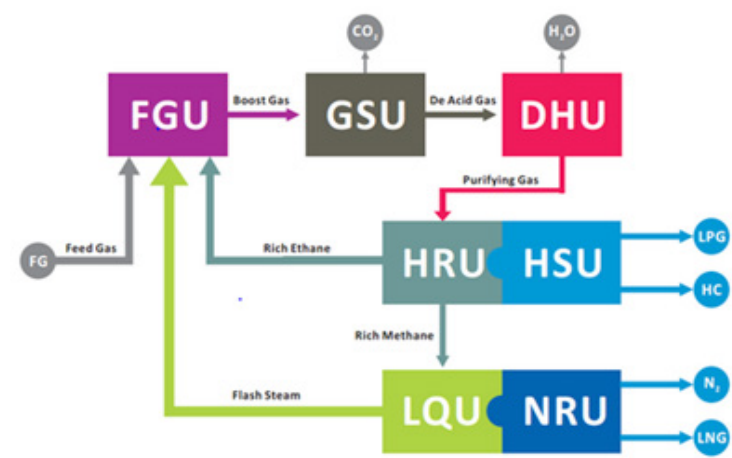

Figure 3. Process Diagram of a typical CNG plant, reproduced from ${ }^{[14]}$; FGU - Flue Gas Unit, GSU - Gas Sweetening Unit, DHU - Dehydration Unit; HRU - Heavies Removal Unit, HSU - Heavies Separation Unit, LQU; Liquefaction Unit; NRU - Nitrogen Rejection Unit 
Commercial application of CNG in process systems is faced with the challenge of storage at high pressures via multi stage compression cycles which requires designs of high pressure storage cylinders that are expensive and costly. Also, there are safety concerns especially when $\mathrm{CNG}$ is used on board vehicles. In all, CNG is faced with drawbacks which limit its applicability at commercial and industrial levels. In addition, CNG possesses low energy density of $8.8 \mathrm{MJ} / \mathrm{L}$ at 200 bar and $20^{\circ} \mathrm{C}$ which is $75 \%$ less than the energy density of gasoline ${ }^{[15]}$ that it seeks to displace in vehicular applications.

\subsubsection{Natural Gas Hydrates (NGH)}

Natural Gas Hydrates (NGH) are ice-like compounds made up of lattice of water with potential positions for guest molecules (in this case methane) at which temperatures and pressures at normal conditions occur in gaseous phase; in NGH, guest molecules possess ability to fit into the interstices of the water-ice lattice ${ }^{[16]}$. Amongst the different types of gas hydrates structures as structure I (sI), structure II (sII), and structure $\mathrm{H}(\mathrm{sH})$ that exist based on the cage structure of the lattice, NGH are regarded as sI as the methane easily fits into the lattice structure. Hence, NGH can be considered to be stable at high pressures and low temperatures therefore they are prevalent in deepwater of water bodies such as oceans. Also, NGH are high energy density compounds which highlights the high hydrocarbon content obtainable from these clathrates. It is reported that if $1 \mathrm{~m}^{3}$ of NGH is dissociation, it would release about $160 \mathrm{~m}^{3}$ of natural gas ${ }^{[17]}$ - the high reserve content of these deposits has facilitated in depth research into commercializing these huge reserves as a sources of primary energy. A typical lattice structure of NGH is shown in Figure 4.

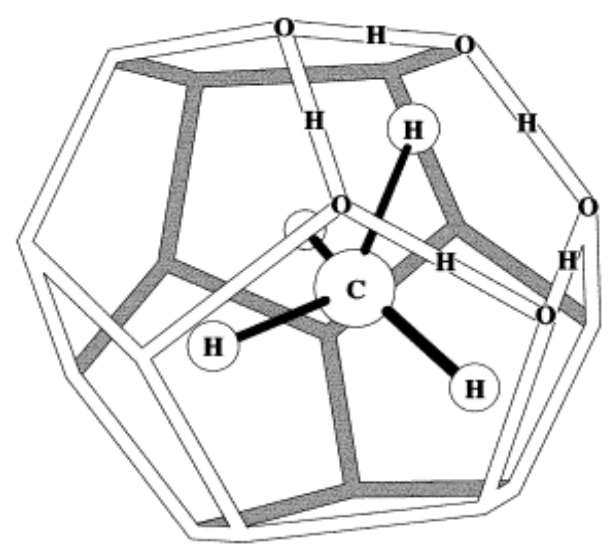

Figure 4. Diagrammatic representation of sI NGH; H hydrogen atom, $\mathrm{O}$ - oxygen atom, $\mathrm{C}$ - carbon atom, filled and unfilled double lines - chemical bonds, reproduced by ${ }^{[18]}$
Although NGH have been identified to be an abundant natural energy source (amount of NGH present in Arctic permafrost and under the oceans collectively represent about $53 \%$ of all fossil fuels present on earth ${ }^{[16]}$, issues of exploration of this energy resource remains a challenge even though pilot tests for exploration has been carried out in Japan and China. Lack of well developed technology and the high cost of deploring it undermine its commercial and industrial applicability.

\subsubsection{Adsorbed Natural Gas (ANG)}

This mechanism of natural gas storage entails packing adsorbents in storage vessels in order to increase their storage capacities for installation onboard vehicles a shown in Figure 5. ANG possess characteristics such as high energy density and environmental friendliness which makes them capable to displace LNG, CNG and NGH for applicability. For instance, it is reported that use of ANG in vehicles emits less CO, NOx and hydrocarbon in the order of $99 \%$, $30 \%$ and $96 \%$ respectively ${ }^{[19]}$. In addition, storage of natural gas in non-cylindrical tanks at pressures of $35-40$ bar affords flexibility in designing placement and configuration of the tank while ameliorating cost of compressing or liquefying natural gas for transportation and storage. Hence, ANG shows potential to be applied in the near future in systems such as gas holders used in peaking shaving LNG plants, drying chambers that are gas fired, solid sorption heat pumps that are also gas fired.

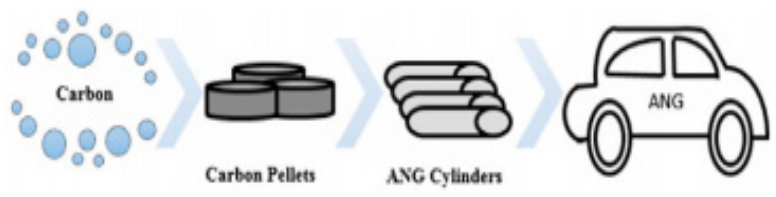

Figure 5. Application of ANG in vehicles, reproduced from $^{[15]}$

The use of adsorbents for storage of adsorbates (in this case methane) is an active area of research. Using adsorption, an process wherein adsorbents adhere adsorbates to their solid surfaces at low pressures and ambient temperatures where applicable via van der Waals or chemical bonds as the case maybe ${ }^{[20]}$ as shown in Figure 5 presents a process and energy efficient option for storage of natural gas. This is due to the fact that adsorbents used for gas storage possess characteristics such as high adsorption capacity, low pressure and ambient storage of gases, thermal, chemical and mechanical stability, regenerability and low of production that make them suitable for commercialization. For instance, it is reported that the isosteric heat of adsorption ranges from $10-100 \mathrm{KJ} / \mathrm{mol}$ depending 
on the type of adsorption (physical or chemical adsorption) ${ }^{[20]}$ highlighting the low energy needed to regenerate the adsorbents and low cost of operation. In this regard, different adsorbents such as activated carbon ${ }^{[21]}$, polymers $^{[22]}$ and metal organic framework (MOF) ${ }^{[7]}$ have been studied for adsorption of methane in literature. Amongst these adsorbents, MOF have been have been revealed to show exceptional properties for methane storage due to its high methane adsorption capacity (arguably regarded as the high methane storage adsorbent) due to very high surface area, selectivity and controlled pore sizes ${ }^{[23]}$. Hence, MOF would be the adsorbent of interest that would be reviewed for methane storage in this review.

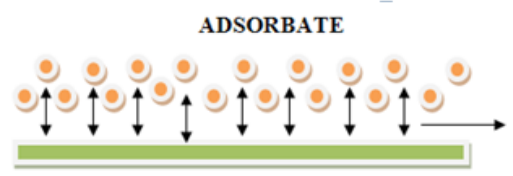

Van der Waals force/chemical bonds that facilitate interaction between adsorbate (methane) and adsorbent

\section{ADSORBENT}

Figure 6. Schematic of adsorption process for gas phases

Considering the different storage mechanisms for methane discussed hitherto, ANG has stood out as the only option that can be applied at conditions close to atmospheric conditions (low pressures and temperatures close to ambient conditions) in less expensive systems of storage and transportation making ANG more attractive for commercialization. However, for LNG, process conditions are cryogenic (temp. of $-161^{\circ} \mathrm{C}$ and 100 bar); $\mathrm{CNG}$ is stored at very high pressures of 200-300bar as a supercritical fluid at room temperature and NGH involves difficult-to-attain conditions for its formation and slow formation rate. Consequently, challenges faced by LNG, CNG and NGH have therefore propelled ANG as the viable storage medium for NG.

\subsection{Mechanism of Hydrogen Storage}

Production of fuel cell vehicles by companies such as Hyundai, Roewe, Riversimple, Toyota and Honda that use hydrogen stored at high pressures of $\sim 700 \mathrm{bar}$ as source of energy is gradually standard in the automobile industry. In addition, other mechanisms of storing hydrogen in process systems (particularly on board vehicles) have been investigated all in a bid to discover the most process and energy efficient storage mechanism for hydrogen and US Department of Energy (DOE) target for on board hydrogen highlighted in Table 1; this is due to the fact that storage mechanism currently being investigated cannot compete with gasoline at low pressures and temperatures. These several storage mechanisms are highlighted below; also, they would be discussed in detail in this section.

(1) Compressed Gaseous storage of hydrogen
(2) Liquid storage of Hydrogen

(3) Solid-state storage of Hydrogen

\subsubsection{Compressed Gaseous Storage of Hydrogen}

Compressed storage of hydrogen entails physical storage of hydrogen gas at high pressures of $350-750$ bar that produces energy content of $4.4 \mathrm{MJ} / \mathrm{L}$ - value less than that obtainable in gasoline $(31.6 \mathrm{MJ} / \mathrm{L})$. Due to some attractive properties of compressed gaseous storage of hydrogen such as low energy for storage, low cost of operation (not as high other types of CNG storage), high speed of release of hydrogen gas at room temperatures and ability to maintain full service even at very low temperatures make this option of hydrogen to be most deployed. In this regard, three applications of hydrogen exist; they are bulk cargo transportation, stationary type and vehicle mounted application. However, use of hydrogen in vehicles is the most deployed ${ }^{[24]}$ - this vehicles, the cylinders used to store hydrogen are made of fiber filament winding composites lined with an inner metal bladder. One of such developed storage tanks is the typical vehicle mounted type IV compressed gaseous hydrogen vessel shown in Figure 7. A tank such as this has the capacity to store hydrogen at pressures of $350-700 \mathrm{bar}$ hence it can attain gravimetric storage capacity of $5 \mathrm{wt} \%$.

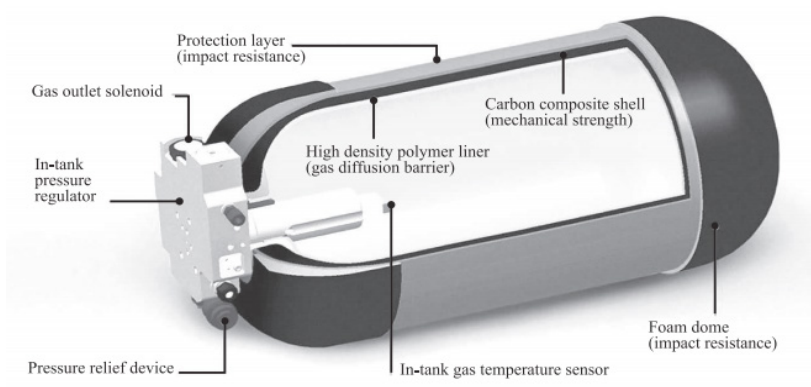

Figure 7. Type IV typical vehicle mounted hydrogen storage vessel, reproduced from ${ }^{[24]}$

Although compressed gaseous storage of hydrogen is one of the most viable option s for storage of hydrogen, the issue of high cost of storage due to costly multistage compression cycles and safety concerns which arises due to high pressure storage limits its rapid commercial deployment. In addition, compressed gaseous storage of hydrogen is volumetrically and gravimetrically ${ }^{[25]}$.

\subsubsection{Liquid Storage of Hydrogen}

This mechanism of storing hydrogen involves compression which then followed by liquefaction at cryogenic condition during which temperature of the gas is reduced to $-252^{\circ} \mathrm{C}$ at vacuum conditions ${ }^{[24]}$. Herein, low tempera-

DOI: https://doi.org/10.30564/jees.v2i2.2642 
ture liquid is stored in a thermally insulated container (that can store $0.070 \mathrm{~kg} / \mathrm{L}$ of hydrogen, even more than CNG tanks which store $0.030 \mathrm{~kg} / \mathrm{L}^{[26]}$ for storage and transportation. As a result of the conditions at which liquid hydrogen stored, it possesses high energy density (mass and volume density) and content (8.4 MJ/L). However, liquid storage of hydrogen is faced with technical challenges that limit its commercial deployment. Firstly, it is energy intensive as a result of energy needed for liquefaction process (it is reported that liquefaction is equal to $30 \%$ of the total hydrogen energy in practical applications). Secondly, thermal insulation of hydrogen storage vessels is difficult to attain to meet specific requirements such design of special materials to be used for insulation and design of the storage vessel. Furthermore, the compulsory venting process in FCVs referred to as Dormancy ${ }^{[27]}$ poses serious challenge to its practical applications.

\subsubsection{Solid-state Storage}

Solid-state storage involves using metal hydrides, complex hydride metals (borohydride) and other materials of high surface for hydrogen storage. This mechanism of storage follows two routes; (i) absorption of hydrogen atoms on metal hydrides via chemical bonds and (ii) adsorption of hydrogen atoms on the high surface area of materials (adsorbents). For metal hydrides, dihydrogen bonds formed when metal hydride (M - H) accept protons from protic hydrogen moiety $(\mathrm{H}-\mathrm{X})$ to form metal complexes $(\mathrm{M}-\mathrm{H} \cdots \mathrm{H}-\mathrm{X})^{[28]}$ as shown in Figure 8 are responsible for hydrogen storage in their framework. The viability with which hydrogen is stored in metal hydrides makes the process intrinsically safe with volumetric capacity higher than that of compressed gaseous and liquid storage of hydrogen ${ }^{[29]}$. Also, metal hydrides possess ability to reversibly store and release (at room temperatures) hydrogen at high storage capacity $(5-7 \mathrm{wt} \%)^{[30]}$; such storage capacity is obtainable at temperatures of $2500^{\circ} \mathrm{C}$ or higher.

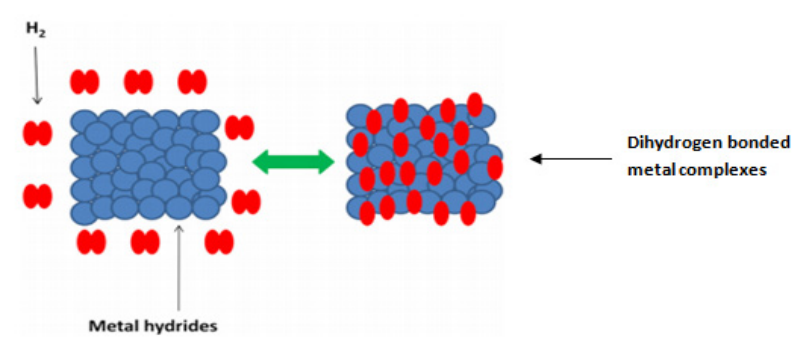

Figure 8. Diagrammatic representation of hydrogen storage in metal hydrides, modified from ${ }^{[26]}$

For adsorbents, physisorption is responsible for facilitating storage of hydrogen. In this regard, target gravimet- ric storage capacities become attainable at low pressures in adsorbents such as carbon nanotubes, activated carbon, graphene containing materials and MOFs etc. Hence, use of adsorbents in cryo-adsorption tanks for improved hydrogen storage at pressures of 350 bar and cryogenic temperatures has become a reality in some prototype fuel cell vehicles produced by BMW. Also, adsorption storage of hydrogen is a fully reversible and rapid process that is hinged on van der Waals force (although other forces such as orbital interactions and electrostatic attraction may influence the process of adsorption ${ }^{[31]}$ hence its heat of adsorption is low translating to ease of management of the process as regards energy consumption for regeneration. In addition, adsorbents investigated for hydrogen storage have been reported to exhibit properties such as ease of functionalization for improved adsorption capacity, mechanical, thermal and chemical stability and good regenerability. Therefore, storage of hydrogen on adsorbents, particularly MOFs (which exhibit exceptional storage capacity for hydrogen at low pressures and temperatures closer to ambient than liquid storage) become attractive as a compound that can meet DOE's target for adsorbed storage of hydrogen. Hence, review of MOFs for hydrogen storage would be focus also be the focus of this review as metal hydrides face challenges such as high cost of high purity metals used in the production of hydrides and the non-reversibility of hydrogen uptake by these compounds.

\section{Metal Organic Framework (MOF)}

Metal-organic frameworks (MOFs) are an exciting and emerging class of porous materials constructed from metal-containing nodes [also known as secondary building units (SBUs)] and organic linkers (ligands) reacted in a solution ${ }^{[32]}$ - basic pathway of synthesis is shown in Figure 9. After synthesis, removal of the solvent produces a porous network that is crystalline whose topology is controlled by the symmetry and coordination of building constituents of the framework. Also, MOFs usually boast a structure with permanent porosity and open crystalline networks due to the presence of strong bonds that exist between SBUs and organic linkers. In addition, these SBUs and ligands can be altered to control pore sizes and surface area of the framework which would influence the availability of active sites for guest molecules adsorption - in this vein, MOFs with properties such as high surface area (up to $10000 \mathrm{~m}^{2} / \mathrm{g}$ ), high porosity (up to $90 \%$ ) and tunable pore sizes for gas storage and separation have been reported ${ }^{[33]}$. 


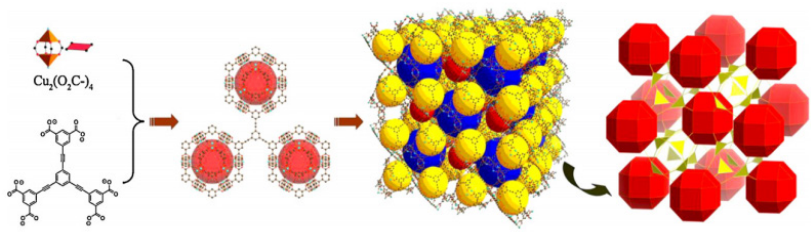

Figure 9. Structure and composition of Metal Organic Framework $^{[32]}$

Furthermore, the ease with which SBUs and organic inkers are altered, selected and functionalized has led to the synthesis of various types and structures of MOFs for gas storage. In this regard, structure and properties of MOFs can then be easily designed and systematically tuned by the judicious choice of building blocks ${ }^{[32]}$, a feat that is rather difficult to achieve in other porous compounds such as zeolites, activated carbon, polymers etc. Hence, MOF have been shown to outperform other traditional porous materials in terms of tunability, ease of functionalization and synthesis for process applications such as gas (methane and hydrogen) storage and separation. Lozano-Castelló et al. corroborated this by stating that while traditional zeolites exhibit methane uptake below $100 \mathrm{~cm}^{3}$ (STP) $\mathrm{cm}^{-3}[34]$ (on a general note, most porous carbon materials exhibit low methane uptake capacity which according to Menon and Komarneni are in the ranges of $50-160 \mathrm{~cm}^{3} / \mathrm{cm}^{3[35]}$, MOFs such as HKUST-1 exhibit methane uptake of $267 \mathrm{~cm}^{3} / \mathrm{cm}^{3}$ at $298 \mathrm{~K}$ and 35 bar $^{[36]}$.

Due to the promising adsorption capacity of MOFs for gas storage, they have been actively investigated by different researchers for methane and hydrogen adsorption ${ }^{[4,7,8,37,38]}$ so as to evaluate their use in specially designed tanks for improved gas storage abilities at low pressures and temperatures closer to ambient than those obtainable in liquefied storage option. The key to this outstanding performance of MOF is the flexible chemistry of the frameworks; these structures can be modified pre - and post - synthetically for improved methane and hydrogen performance; several methods such as open metal dense sites (OMSs), post synthetic modification [functional groups such as amino groups, pendant aldehyde and azides are incorporated into the MOF structure], post synthetic metalation ${ }^{[39]}$ and post synthetic metal ion and ligand exchange have been reported as pathways through which adsorption capacity and overall performance of MOFs for gas storage can be improved.

In this vein, some MOFs structures have been reported to be good candidates for methane storage while others show promising potential for hydrogen storage depending on structure design and chemistry ${ }^{[4]}$. For methane storage, such MOFs include $\mathrm{M}_{2}$ (dicarboxylate) $)_{2}$ dabco frameworks
${ }^{[40]}, \mathrm{Zn}_{4} \mathrm{O}$-based MOFs ${ }^{[41] 3,6-8,32-34}$, copper carboxylates frameworks ${ }^{[36]}$, MIL-series ${ }^{[42]}$ and Zr-based frameworks (reported to be stable in the presence of water even though they do not exhibit storage capacity as high as benchmark MOFs in methane storage) ${ }^{[7]}$ while for hydrogen storage, high performing MOFs are those that possess (1) Open metal sites (OMSs) with low coordination number (2) extra framework cations (3) ultra surface area and (4) high void fraction in the framework.

\section{Adsorption-based Storage of Methane and Hydro- gen in Tanks - MOFs Shows Capacity to Attain}

For methane and hydrogen to compete with conventional energy sources such as gasoline for deployment especially in on board vehicle applications via adsorption-based tank storage, certain targets set by US Department of Energy's (DOE) Advanced Research Projects Agency-Energy (ARPA-E) ${ }^{[43]}$ and Fuel Cells Technology Office ${ }^{[44]}$ have to be met. For methane, a gravimetric target has been set at 0.5 $\mathrm{g}_{\text {(methane) }} \mathrm{g}_{\text {(sorbent) }}$ or $700 \mathrm{~cm}_{\text {(methane) }}^{3} \mathrm{~g}_{\text {(sorbent) }}^{-1}$ at $25^{\circ} \mathrm{C}$ and 65 bar translating to a volumetric capacity of $263 \mathrm{~cm}^{3}$ (STP) $\mathrm{cm}^{-3}$ when the density of methane $\left(\rho=0.188 \mathrm{~g} / \mathrm{cm}^{3}\right.$ at 250 bar) is used as a reference. However, when considering a packing loss of $25 \%$ due to pelletization of MOF powder, the initial uptake capacity for methane based on the set target will have to be $330 \mathrm{~cm}^{3}$ (STP) $\mathrm{cm}^{-3}$ [4] For hydrogen, the targets are $0.045 / 0.055 \mathrm{kgH}_{2} / \mathrm{kg}$ for $2020 / 2025$ on gravimetric capacity and $1.0 / 1.3 \mathrm{kgH}_{2} / \mathrm{L}$ for $2020 / 2025$ for volumetric capacity respectively at temperature range of $-40 / 60^{\circ} \mathrm{C}$ as highlighted in Table 1.

Table 1. Technical targets for adsorption based hydrogen storage in light duty vehicles, adopted from ${ }^{[44]}$

\begin{tabular}{|c|c|c|c|c|}
\hline $\mathbf{S} / \mathbf{N}$ & Storage Parameter & 2020 & 2025 & Ultimate \\
\hline 1 & $\begin{array}{c}\text { Gravimetric capacity (usable specific } \\
\left.\text { energy from } \mathrm{H}_{2}\right)\left(\mathrm{kg} \mathrm{H}_{2} / \mathrm{kg}\right) \\
\text { Volumetric capacity }(\text { usable specific } \\
\left.\text { energy from } \mathrm{H}_{2}\right)\left(\mathrm{kg} \mathrm{H}_{2} / \mathrm{L}\right)\end{array}$ & $\begin{array}{c}0.045 \\
1.0\end{array}$ & $\begin{array}{c}0.055 \\
1.3\end{array}$ & $\begin{array}{c}0.065 \\
1.7\end{array}$ \\
\hline 2 & Temperature of operation $\left({ }^{\circ} \mathrm{C}\right)$ & $\begin{array}{l}-40 / 60 \\
\text { (sun) }\end{array}$ & $\begin{array}{l}-40 / 60 \\
(\text { sun })\end{array}$ & $\begin{array}{l}-40 / 60 \\
(\operatorname{sun})\end{array}$ \\
\hline 3 & $\begin{array}{c}\text { Tank minimum and maximum } \\
\text { delivery temperature of } \mathrm{H}_{2}\left({ }^{\circ} \mathrm{C}\right)\end{array}$ & $-40 / 85$ & $-40 / 85$ & $-40 / 85$ \\
\hline 4 & $\begin{array}{l}\text { Minimum and maximum delivery } \\
\text { pressure from storage system (bar) }\end{array}$ & $5 / 12$ & $5 / 12$ & $5 / 12$ \\
\hline 5 & $\begin{array}{l}\text { Time for system to be filled } \\
\text { (minutes) }\end{array}$ & $3-5$ & $3-5$ & $3-5$ \\
\hline 6 & $\begin{array}{l}\text { Target loss for boil off (maximum } \\
\text { reduction after } 30 \text { days from initial } \\
95 \% \text { of usable capacity) }(\%)\end{array}$ & 10 & 10 & 10 \\
\hline
\end{tabular}

In order to meet these targets, use of outstanding adsorbents such as MOFs is imperative. For methane adsorption -based tank storage, MOF remain the only adsorbent that has shown adsorption capacity closest to DOE's tar- 
get; methane adsorption capacity of $267 \mathrm{~cm}^{3} / \mathrm{cm}^{3}$ at $25^{\circ} \mathrm{C}$ and 65 bar has been reported against $330 \mathrm{~cm}^{3} / \mathrm{cm}^{3}$ at same conditions by MOF HKUST- ${ }^{[36]}$. The same applies for hydrogen storage - MOFs have shown deliverable adsorption capacity of $1-2 \mathrm{wt} \%$ at target process conditions, one of the closest values to DOE's target. Nonetheless, it is important to state that hydrogen storage at atmospheric pressure ( $\sim 1$ bar) and cryogenic temperature is impractical due to the very low adsorption capacity recorded at such conditions (MOF PCN-12 is considered a benchmark that records one of the highest total hydrogen uptake of $23.2 \mathrm{~g} /$ $\mathrm{L}$ or $3.05 \mathrm{wt} \%$ at such conditions ${ }^{[45]}$ ); this can be attributed to van der Waals forces (that facilitate hydrogen-framework interaction) that become weaker at temperatures close to ambient and low pressures.

\section{Methane and Hydrogen Adsorption Capac- ity of MOFs}

The adsorption (herein regarded as delivery capacity) of MOF is a very important factor that influences it use for commercial applications ${ }^{[7]}$. The delivery capacity is the amount of gas stored in the adsorbent between the upper working pressure and the lower working pressure at constant/varying temperatures. For methane storage in natural gas vehicles, the engine working pressure (5 bar) is considered as the lower working pressure ${ }^{[46]}$ while the upper working pressure is considered to be 65 or 35 bar as it can be actualized by using a single or two stage compressor, which is cost effective as the case maybe. Also, the upper working pressure is usually kept at higher pressures because this translates to the storage of a higher amount of methane at a particular temperature. For high pressure cryogenic hydrogen storage, its delivery pressure is set at 100 bar in line with on DOE's target.

For methane, certain MOFs as highlighted in Table 2 have shown great promise for storage at pressures of 65 bar and 35 bar and delivery pressure at 5 bar respectively. In these MOFs, it is evident through computational studies that designing structures with ultrahigh surface areas (ranging from $2500-3000 \mathrm{~m}^{2} / \mathrm{g}$ ), void fraction of around 0.8 and optimal pore diameter of $4-8 \AA^{[47]}$ results in improved volumetric and gravimetric methane uptake. However, it is also shown that when high surface area is combined mesopores, low gravimetric uptake is reported while in the presence of high surface area and micropores, higher gravimetric uptake is recorded ${ }^{[4]}$. For volumetric uptake capacity, presence of open metal sites and pore sizes of smaller diameter strongly determine uptake capabilities. This is evident for MOF-519 ${ }^{[48]}$ wherein a high volumetric capacity is recorded in the presence of limited pore sizes facilitated by BTB moieties that are partially uncoordinated 1,3,5-Tris(4-carboxyphenyl)benzene and absence of OMSs which consequently produces primary adsorption active sites are pressure of 5 bar - thereby increasing the deliverable capacity. In addition, it is reported that modification of pristine MOF with functional groups such as methyl-, ethyl- and t-butyl-groups increased methane uptake of MOFs ${ }^{[49]}$.

Table 2. MOFs for Methane storage and delivery at $25^{\circ} \mathrm{C}$

\begin{tabular}{|c|c|c|c|c|c|c|c|c|c|}
\hline \multirow{2}{*}{ MOF } & \multicolumn{2}{|c|}{$\begin{array}{c}\text { Volumetric } \\
\text { uptake }\left(\mathrm{cm}^{3} /\right. \\
\left.\mathrm{cm}^{3}\right)\end{array}$} & \multicolumn{2}{|c|}{$\begin{array}{c}\text { Volumetric } \\
\text { delivery } \\
\left(\mathrm{cm}^{3} / \mathrm{cm}^{3}\right)\end{array}$} & \multicolumn{2}{|c|}{$\begin{array}{l}\text { Gravimetric } \\
\text { uptake }(g / g)\end{array}$} & \multicolumn{2}{|c|}{$\begin{array}{c}\text { Gravimetric } \\
\text { delivery }(g / g)\end{array}$} & \multirow{2}{*}{ Ref } \\
\hline & 65 bar & 35 bar & $\begin{array}{c}65-5 \\
\text { bar }\end{array}$ & $\begin{array}{c}35-5 \\
\text { bar }\end{array}$ & $65 \mathrm{bar}$ & 35 bar & $\begin{array}{c}65-5 \\
\text { bar }\end{array}$ & $\begin{array}{c}35-5 \\
\text { bar }\end{array}$ & \\
\hline HKUST-1 & 267 & 211 & 190 & 150 & 0.216 & - & 0.154 & - & {$[36]$} \\
\hline MOF-519 & 259 & 200 & 210 & 151 & 0.194 & - & 0.157 & - & [48] \\
\hline Al-soc-MOF-1 & 197 & 127 & 176 & 106 & 0.415 & - & 0.371 & - & {$[50]$} \\
\hline PCN-14 & 230 & 195 & 157 & 125 & - & - & - & - & [36] \\
\hline UTSA-88a & 248 & 204 & 185 & 141 & - & - & - & - & {$[51]$} \\
\hline Ni-MOF-74 & 251 & 228 & 129 & 115 & - & - & - & - & {$[36]$} \\
\hline MAF-38 & 263 & 226 & 187 & 150 & - & - & - & - & {$[52]$} \\
\hline NU-800 & 232 & 174 & 197 & 139 & - & - & - & - & [49] \\
\hline
\end{tabular}

For hydrogen storage, selected MOFs have shown promising adsorption capacity (which in the true sense is the delivery capacity - difference in adsorption capacity between hydrogen uptake at $\sim 100$ bar and $-196^{\circ} \mathrm{C}$ and hydrogen release to 5 bar and $-113^{\circ} \mathrm{C}$ ) in line with Chahine rule (increase in surface area of adsorbent results in $1 \mathrm{wt} \%$ excess adsorption of hydrogen) till surface area increases to $\sim 3000 \mathrm{~m}^{2} / \mathrm{g}^{[53]}$ as shown in Figure 10. Also, highlighted in Table 3, this trend posits that gravimetric adsorption capacity of MOF is proportional to void fraction, pore size and gravimetric surface area. Gómez-Gualdrón et al. highlights this in their study in which they reported that the experimental hydrogen storage capacity of MOF sheMOF-x recorded at cryo-adsorption conditions is dependent on the pore volumes of the structure ${ }^{[54]}$. Also, heat of enthalpy plays a major role in the hydrogen adsorption capacity of MOFs - optimum heat of adsorption is stated to range from -15 to $-20 \mathrm{KJ} / \mathrm{mol}$ for reasonable hydrogen storage to be achieved especially at ambient conditions ${ }^{[55]}$. Furthermore, it has been reported that introduction of OMSs into the framework and their respective alignment strongly influences hydrogen-framework interactions ${ }^{[45]}$. Finally, the presence of small pore sizes that are well 
suited for hydrogen molecules and also prompt improved overlapping potential have been reported to increase framework hydrogen uptake of MOFs ${ }^{[56]}$.

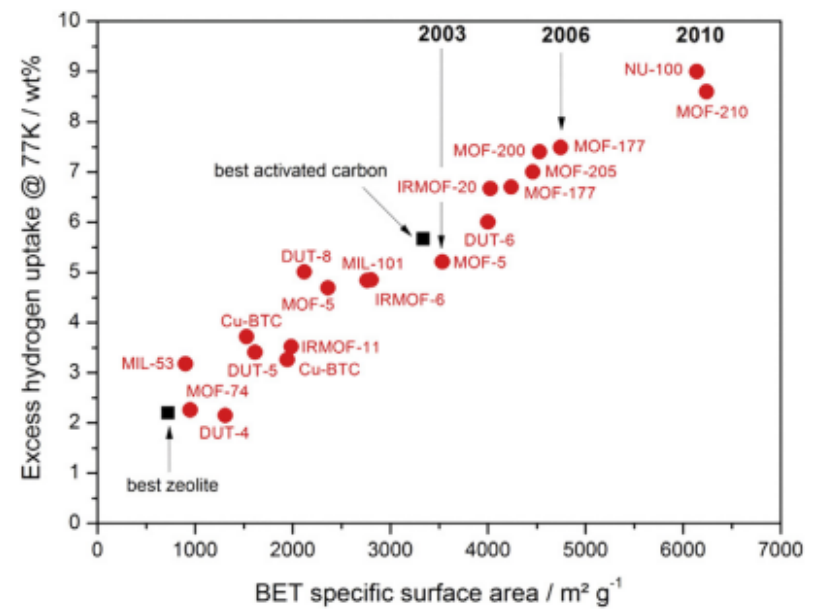

Figure 10. Measurement of adsorption capacity different adsorbents particularly MOF in line with Chahine rule, reproduced from ${ }^{[57]}$

Table 3. Deliverable hydrogen adsorption capacity in $\mathrm{MOF}$ at cryo-adsorption conditions $\left[-196^{\circ} \mathrm{C}\right.$ and $\sim 100 \mathrm{bar}$ although (variable)] and desorption conditions $\left(-113^{\circ} \mathrm{C}\right.$ and 5 bar)

\begin{tabular}{|c|c|c|c|c|c|}
\hline MOF & $\mathbf{S A ~}\left(\mathbf{m}^{2} / \mathbf{g}\right)$ & $\begin{array}{c}\text { Volumetric } \\
\text { capacity (g/L) }\end{array}$ & $\begin{array}{c}\text { Gravimetric } \\
\text { capacity (wt } \%)\end{array}$ & $\begin{array}{c}\text { Void } \\
\text { Fraction }\end{array}$ & Ref. \\
\hline she-MOF-1 & 4300 & 43.4 & 12.5 & - & {$[54]$} \\
\hline NU-1103 & 6246 & 43.2 & 12.6 & - & {$[54]$} \\
\hline MOF-5 & 3512 & 51.9 & 7.8 & 0.81 & {$[58]$} \\
\hline IRMOF-20 & 4073 & 51 & 9.1 & 0.84 & {$[58]$} \\
\hline NU-125 & - & 49 & 8.5 & - & {$[53]$} \\
\hline SNU-70 & 4944 & 47.9 & 10.6 & 0.86 & {$[58]$} \\
\hline UMCM-9 & 5039 & 47.4 & 11.3 & 0.86 & {$[58]$} \\
\hline
\end{tabular}

\section{Computational and Molecular Simulation Studies of Methane and Hydrogen Storage}

In order to abate high cost of carrying out experimental works as regards synthesis of MOFs for methane and hydrogen storage, computational design and molecular studies of hypothetical MOFs have been increasingly carried out to determine their structure-property for gas storage; a study by Gómez-Gualdrón ${ }^{[54]}$ reported construction of 13512 MOFs which were evaluated for cryo-adsorption of hydrogen while Wilmer et al. reported construction of
137953 hypothetical MOFs for methane adsorption ${ }^{[47]}$. In this vein, particular attention has been paid to designing of MOFs of specific topologies that can provide active sites for guest molecules; herein careful selection of organic linkers and SBUs that are fitted to pre-determined topologies via an automated algorithm.

For construction of hypothetical MOFs, different approaches are utilized. While some researchers use a downtop approach by building the crystal structure from building blocks and SBUs till the structure is formed, others approach construction from a top-down method in which selected building blocks are connected to a pre-determined topological blueprint. For the down-top approach whose pathway is shown in Figure 11, crystallographic data of known synthesized MOFs is used to select building blocks that are combined based on local geometry and chemical composition that must be the same. The process of building continues stepwise until an atomic overlap occurs during a different building block is used and the process continues ${ }^{[47]}$. In this process, a periodic boundary formed by connecting two building blocks is sometimes imposed instead of adding a new building block. Also, minimization of force fields or quantum mechanical energy is carried in this approach - down-top approach is governed by geometric rules that synthesis of existing MOFs from various building blocks. Thereafter, validation of the hypothetical MOF is carried out; herein certain aspects of the crystal structure such as its minimum energy, fitness of hypothetical structure to those synthesized experimentally and sensitivity of physical properties of hypothetical structures to experimental ones are evaluated - physical properties usually considered are topology of framework, limiting diameter of pore sizes, diameter of largest cavity, accessible pore volume, accessible surface area, equilibrium gas loading capacity and Henry's law constant. Hence, a comparison of the hypothetical structures with those that are energetically relaxed through minimization of force fields is carried out; same is done for experimentally synthesized MOFs. Also, predicted gas adsorption capacities of hypothetical structures are compared with those that are experimental synthesized. Significantly, it has been reported that the predicted adsorption capacity of most hypothetical MOFs are close to their experimentally synthesized counterparts as shown in Figure 12 - the values of hydrogen adsorption isotherms (measured in $\mathrm{mmol} / \mathrm{g}$ ) of simulated and experimental NU-125 at temperatures of $-196^{\circ} \mathrm{C},-113^{\circ} \mathrm{C}$ and $23^{\circ} \mathrm{C}$ show excellent agreement.

The use of down-top approach for MOF structure construction faces the challenge of producing MOFs with limited topologies. This is reported by Sikora et al. in their work in which they revealed that out of 137000 hypotheti- 
cal MOFs constructed ( $90 \%$ of MOFs produced), only six topologies of primitive pcu topology were produced ${ }^{[59]}$. Also, some expected topologies were not realized hence, the top-down approach becomes attractive as it been reported to ameliorate this drawback. This computational method involves matching of symmetry and connectivity of the nodes of pre-selected topology of the structures and their respective building blocks. In other works, top-down approach entails selection of the appropriate template and topology to which selected building blocks would be added in stepwise manner. This is followed by scaling of unit cells of the topology based on the targeted building block that is to be added. Here after, organic and inorganic nodes and organic linkers are added; the structure obtained would then be optimized using classical force field optimization. Finally, the physical properties of the hypothetical MOF are evaluated. The ability of top-down approach to produce hypothetical MOFs have been reported by Gómez-Gualdrón et al. ${ }^{[54]}$; in their work, they reported that out of 13512 MOFs constructed, 41 different topologies were recorded.

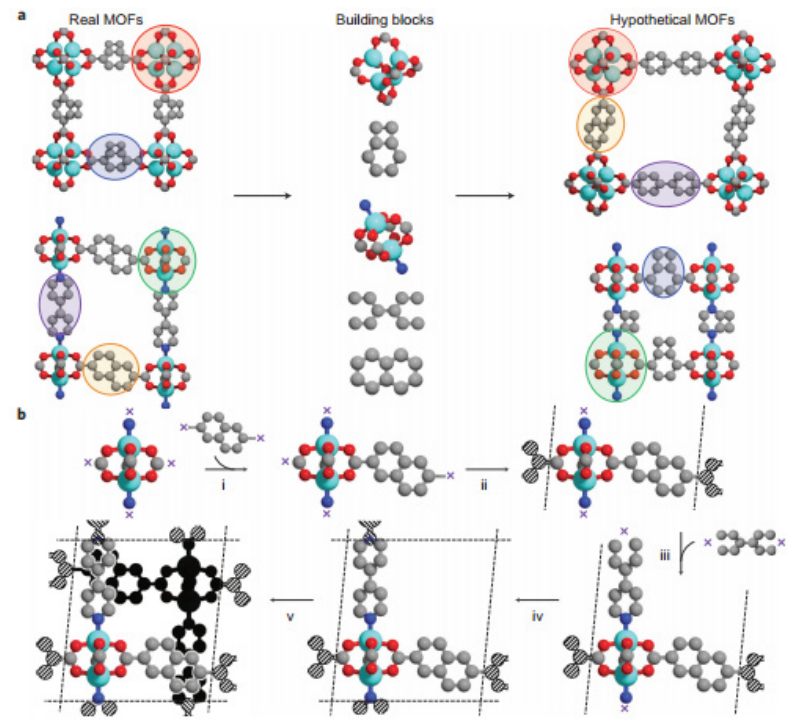

Figure 11. Pathway for construction of hypothetical MOFs in down-top approach, reproduced from ${ }^{[47]}$; $a$ pathway for synthesis of hypothetical MOFs, $b$ - pathway for stepwise construction of hypothetical MOFs from building blocks; purple Xs - sites of connection, hashed circle mirror images - periodic boundaries, grey - carbon atom, red sphere - oxygen atom, blue sphere - nitrogen atom, turquoise sphere - zinc atom

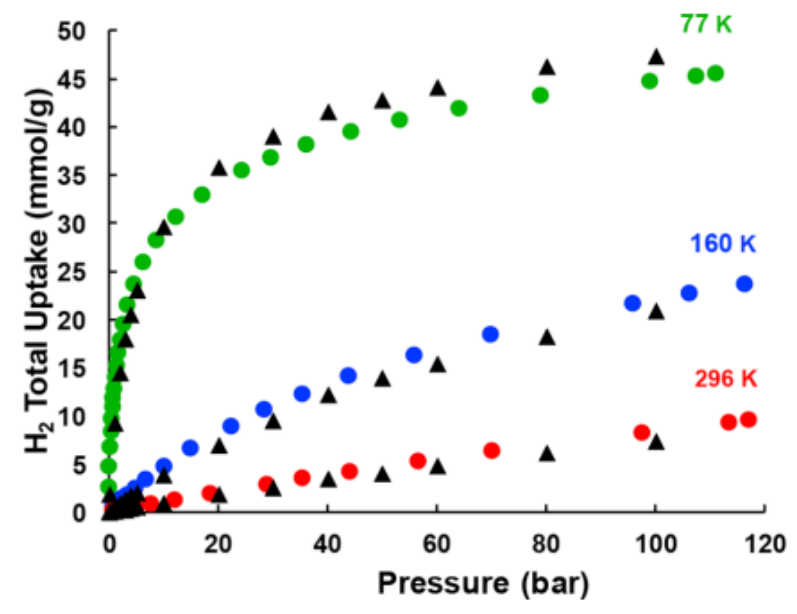

Figure 12. Simulated (triangles) and measured (circles) adsorption isotherms of NU-125, reproduced from ${ }^{[53]}$

\section{Conclusion}

The importance of clean energy sources such as methane and hydrogen for environmental sustainability and actualization of a net zero carbon emission future has been highlighted. Hence in this mini review, different mechanisms for storing methane and hydrogen in commercial applications especially on board vehicle storage to increase their storage capacities for improved performance so as to challenge conventional energy sources for deployment were discussed. Herein, suitability of adsorption-based storage of methane and hydrogen in specially designed tanks was highlighted. In this regard, MOFs were revealed as the most promising adsorbent that can achieve the ambitious targets set by US DOE's Advanced Research Projects Agency-Energy (ARPA-E) and Fuel Cells Technology Office. Hence, selected high performing MOFs for methane and hydrogen storage were highlighted and trends of research that facilitate their occurrence were discussed. In addition, computation and molecular studies of hypothetical MOFs were discussed - trends of research in this field were discussed and methodologies to construct MOFs of designated topologies and physical properties were revealed.

\section{References}

[1] A. Dechezleprêtre, M. Glachant, I. Haščič, N. Johnstone, Y. Ménière. Invention and transfer of climate change-mitigation technologies: A global analysis. Rev. Environ. Econ. Policy, 2011, 5: 109-130.

DOI: 10.1093/reep/req023

[2] F. Joos, R. Spahni. Rates of change in natural and anthropogenic radiative forcing over the past 20,000 years. PNAS, 2008, 105: 1425-1430. 
[3] National Oceanic and Atmospheric Administration, Monthly Average Mauna Loa CO2, 2020. https://www.esrl.noaa.gov/gmd/ccgg/trends/

[4] A. Schoedel, Z. Ji, O.M. Yaghi. The role of metal-organic frameworks in a carbon-neutral energy cycle. Nat. Energy, 2016, 1: 1-13.

DOI: 10.1038/nenergy.2016.34

[5] The NEED Project, Natural Gas, 2018. https://www.need.org/Files/curriculum/infobook/ NGasS.pdf

[6] L. Arnold, G. Averlant, S. Marx, M. Weickert, U. Müller, J. Mertel, C. Horch, M. Peksa, F. Stallmach. Metal organic frameworks for natural gas storage in vehicles. Chemie-Ingenieur-Technik, 2013, 85: 17261733.

DOI: $10.1002 /$ cite.201300093

[7] Y. He, W. Zhou, G. Qian, B. Chen. Methane storage in metal-organic frameworks. Chem. Soc. Rev., 2014, 43: 5657-5678.

DOI: $10.1039 / \mathrm{c} 4 \mathrm{cs} 00032 \mathrm{c}$

[8] M.P. Suh, H.J. Park, T.K. Prasad, D.W. Lim. Hydrogen storage in metal-organic frameworks. Chem. Rev., 2012, 112: 782-835.

DOI: 10.1021/cr200274s

[9] Office of Energy Efficiency \& Renewable Energy, Hydrogen Storage - Basics, Hydrog. Fuel Cell Technol. Off, 2020.

https://www.energy.gov/eere/fuelcells/hydrogen-storage-basics-0 (accessed November 27, 2020).

[10] A. Yamashita, M. Kondo, S. Goto, N. Ogami. Development of High-Pressure Hydrogen Storage System for the Toyota "Mirai," SAE Tech. Pap. Ser. 1, 2015. DOI: 10.4271/2015-01-1169

[11] L.N.G. Plant, R.T. Operations, LNG Plant and Regasification Terminal Operations. Handb. Liq. Nat. Gas, 2014: 297-320.

DOI: 10.1016/B978-0-12-404585-9.00007-6

[12] S.S. Ikiensikimama, LNG Liquefaction Systems Comparison [Powerpoint Presentation], 2019.

[13] M.I. Khan, T. Yasmin, A. Shakoor. Technical overview of compressed natural gas (CNG) as a transportation fuel, Renew. Sustain. Energy Rev., 2015, 51: 785-797.

\section{DOI: 10.1016/j.rser.2015.06.053}

[14] Peiyang Chemical Eng. Co., CNG Plant, 2020. https://www.peiyangchem.com/modular-gas-processing/cng-plant.html (accessed November 30, 2020).

[15] S. Alhasan, R. Carriveau, D.S.K. Ting. A review of adsorbed natural gas storage technologies, Int. J. Environ. Stud. 2016, 73: 343-356.

DOI: 10.1080/00207233.2016.1165476

[16] A. Demirbas. Methane Gas Hydrate: as a Natural
Gas Source, Springer, 2010.

DOI: 10.1007/978-1-84882-872-8_4

[17] A.M. Gambelli, F. Rossi. Natural gas hydrates: Comparison between two different applications of thermal stimulation for performing $\mathrm{CO} 2$ replacement. Energy, 2019, 172: 423-434.

DOI: 10.1016/j.energy.2019.01.141

[18] W.P. Dillon. Gas Hydrate in the Ocean Environment. Encycl. Phys. Sci. Technol., 2002, 473-486.

DOI: 10.1016/b0-12-227410-5/00276-3

[19] L.L. Vasiliev, L.E. Kanonchik, D.A. Mishkinis, M.I. Rabetsky. Adsorbed natural gas storage and transportation vessels, Int. J. Therm. Sci., 2000, 39: 10471055.

DOI: 10.1016/S1290-0729(00)01178-9

[20] E. Musin. Adsorption Modelling, Mikelli University of Applied Sciences, 2013.

[21] N. Bagheri, J. Abedi. Adsorption of methane on corn cobs based activated carbon. Chem. Eng. Res. Des., 2011, 89: 2038-2043.

DOI: 10.1016/j.cherd.2011.02.002

[22] R.L. Martin, C.M. Simon, B. Smit, M. Haranczyk. In silico design of porous polymer networks: High-throughput screening for methane storage materials. J. Am. Chem. Soc., 2014, 136: 5006-5022. DOI: 10.1021/ja4123939

[23] Y. Lin, C. Kong, Q. Zhang, L. Chen. Metal-Organic Frameworks for Carbon Dioxide Capture and Methane Storage. Adv. Energy Mater, 2017, 7.

DOI: 10.1002/aenm.201601296

[24] Y.H. Zhang, Z.C. Jia, Z.M. Yuan, T. Yang, Y. Qi, D.L. Zhao. Development and Application of Hydrogen Storage. J. Iron Steel Res. Int., 2015, 22: 757-770.

DOI: 10.1016/S1006-706X(15)30069-8

[25] Y. Li, R.T. Yang. Significantly enhanced hydrogen storage in metal-organic frameworks via spillover. J. Am. Chem. Soc., 2006, 128: 726-727.

DOI: $10.1021 / j a 056831 s$

[26] S. Niaz, T. Manzoor, A.H. Pandith. Hydrogen storage: Materials, methods and perspectives. Renew. Sustain. Energy Rev., 2015, 50: 457-469.

DOI: 10.1016/j.rser.2015.05.011

[27] U. Eberle, M. Felderhoff, F. Schüth. Chemical and physical solutions for hydrogen storage, Angew. Chemie - Int. Ed. 2009, 48: 6608-6630.

DOI: 10.1002/anie.200806293

[28] N. V. Belkova, L.M. Epstein, O.A. Filippov, E.S. Shubina. Hydrogen and Dihydrogen Bonds in the Reactions of Metal Hydrides. Chem. Rev., 2016, 116: 8545-8587.

DOI: 10.1021/acs.chemrev.6b00091

[29] G. Principi, F. Agresti, A. Maddalena, S. Lo Russo. 
The problem of solid state hydrogen storage. Energy, 2009, 34: 2087-2091.

DOI: 10.1016/j.energy.2008.08.027

[30] R. Schulz, J. Huot, G.X. Liang, S. Boily, A. Van Neste. Structure and Hydrogen Sorption Properties of Ball Milled Mg Dihydride. J. Metastable Nanocrystalline Mater, 1999, 2-6: 615-622.

DOI: 10.4028/www.scientific.net/jmnm.2-6.615

[31] E. Klontzas, E. Tylianakis, G.E. Froudakis. On the enhancement of molecular hydrogen interactions in nanoporous solids for improved hydrogen storage. J. Phys. Chem. Lett., 2011, 2: 1824-1830.

DOI: 10.1021/jz2005368

[32] J. Li, Y. Ma, M.C. Mccarthy, J. Sculley, J. Yu, H. Jeong, P.B. Balbuena, H. Zhou. Carbon dioxide capture-related gas adsorption and separation in metal-organic frameworks. Coord. Chem. Rev., 2011, 255: 1791-1823.

DOI: 10.1016/j.ccr.2011.02.012

[33] H. Furukawa, K.E. Cordova, M. O'Keeffe, O.M. Yaghi. The chemistry and applications of metal-organic frameworks. Science (80-. ), 2013, 341.

DOI: 10.1126/science.1230444

[34] D. Lozano-Castelló, J. Alcañiz-Monge, M.A. De La Casa-Lillo, D. Cazorla-Amorós, A. Linares-Solano. Advances in the study of methane storage in porous carbonaceous materials. Fuel, 2002, 81: 1777-1803.

DOI: 10.1016/S0016-2361(02)00124-2

[35] V.C. Menon, S. Komarneni. Porous Adsorbents for Vehicular Natural Gas Storage: A Review. J. Porous Mater, 1998, 5: 43-58.

[36] Y. Peng, V. Krungleviciute, I. Eryazici, J.T. Hupp, O.K. Farha, T. Yildirim. Methane storage in metal-organic frameworks: Current records, surprise findings, and challenges. J. Am. Chem. Soc., 2013, 135: 11887-11894.

\section{DOI: $10.1021 / j a 4045289$}

[37] R. Balderas-Xicohténcatl, M. Schlichtenmayer, M. Hirscher. Volumetric Hydrogen Storage Capacity in Metal-Organic Frameworks. Energy Technol., 2018, 6: $578-582$.

\section{DOI: 10.1002/ente.201700636}

[38] V.R. Bakuru, M.E. DMello, S.B. Kalidindi. Metal-Organic Frameworks for Hydrogen Energy Applications: Advances and Challenges. Chem Phys Chem, 2019, 20: 1177-1215.

DOI: 10.1002/cphc.201801147

[39] J.D. Evans, C.J. Sumby, C.J. Doonan. Post-synthetic metalation of metal-organic frameworks, Chem Soc Rev., 2014: 5933-5951.

DOI: $10.1039 / \mathrm{c} 4 \mathrm{cs} 00076 \mathrm{e}$

[40] I. Senkovska, S. Kaskel. High pressure methane ad- sorption in the metal-organic frameworks $\mathrm{Cu} 3(\mathrm{btc}) 2$, $\mathrm{Zn} 2$ (bdc)2dabco, and $\mathrm{Cr} 3 \mathrm{~F}(\mathrm{H} 2 \mathrm{O}) 2 \mathrm{O}(\mathrm{bdc}) 3$. Microporous Mesoporous Mater, 2008, 112:108-115.

DOI: 10.1016/j.micromeso.2007.09.016

[41] M. Eddaoudi, J. Kim, N. Rosi, D. Vodak, J. Wachter, M. O'Keeffe, O.M. Yaghi. Systematic Design of Pore Size and Functionality in Isoreticular MOFs and Their Application in Methane Storage. Science (80-.), 2002, 5554: 469-472.

DOI: 10.1126/science.1067208

[42] P. Rallapalli, K.P. Prasanth, D. Patil, R.S. Somani, R. V. Jasra, H.C. Bajaj. Sorption studies of CO2, CH4, $\mathrm{N} 2, \mathrm{CO}, \mathrm{O} 2$ and $\mathrm{Ar}$ on nanoporous aluminum terephthalate [MIL-53(Al)], J. Porous Mater. 2011 18: 205-210.

\section{DOI: 10.1007/s10934-010-9371-7}

[43] ARPA-E, MOVE Program Overview, 2012. https://arpa-e.energy.gov/sites/default/files/documents/files/MOVE_ProgramOverview.pdf

[44] Office of Energy Efficiency \& Renewable Energy. Technical Targets for Onboard Hydrogen Storage for Light-Duty Vehicles, Hydrog. Fuel Cell Technol. Off, 2020.

https://www.energy.gov/eere/fuelcells/doe-technical-targets-onboard-hydrogen-storage-light-duty-vehicles (accessed November 27, 2020).

[45] X.-S. Wang, S. Ma, P.M. Forster, D. Yuan, J. Eckert, J.J. López, B.J. Murphy, J.B. Parise, H.-C. Zhou. Enhancing H2 Uptake by "Close-Packing" Alignment of Open Copper Sites in Metal-Organic Frameworks, Angew. Chemie, 2008, 120: 7373-7376.

DOI: 10.1002/ange.200802087

[46] J.A. Mason, M. Veenstra, J.R. Long. Evaluating metal-organic frameworks for natural gas storage. Chem, Sci., 2014, 5: 32-51.

DOI: $10.1039 / \mathbf{c 3 s c 5 2 6 3 3 j}$

[47] C.E. Wilmer, M. Leaf, C.Y. Lee, O.K. Farha, B.G. Hauser, J.T. Hupp, R.Q. Snurr. Large-scale screening of hypothetical metal-organic frameworks. Nat. Chem., 2012, 4: 83-89. DOI: 10.1038/nchem.1192

[48] F. Gándara, H. Furukawa, S. Lee, O.M. Yaghi. High Methane Storage Capacity in Aluminum Metal-Organic Frameworks. J. Am. Chem. Soc., 2014, 136: 5271-5274.

https://doi.org/10.1021/ja501606h

[49] D.A. Gómez-Gualdrón, C.E. Wilmer, O.K. Farha, J.T. Hupp, R.Q. Snurr. Exploring the limits of methane storage and delivery in nanoporous materials. J. Phys. Chem. C, 2014, 118: 6941-6951.

DOI: 10.1021/jp502359q

[50] D. Alezi, Y. Belmabkhout, M. Suyetin, P.M. Bhatt, L.J. Weseliński, V. Solovyeva, K. Adil, I. Spanopou- 
los, P.N. Trikalitis, A.H. Emwas, M. Eddaoudi. MOF Crystal Chemistry Paving the Way to Gas Storage Needs: Aluminum-Based soc -MOF for CH4, O2, and CO2 Storage. J. Am. Chem. Soc., 2015, 137: 13308-13318.

DOI: 10.1021/jacs.5b07053

[51] G. Chang, B. Li, H. Wang, Z. Bao, T. Yildirim, Z. Yao, S. Xiang, W. Zhou, B. Chen. A microporous metal-organic framework with polarized trifluoromethyl groups for high methane storage. Chem. Commun. 2015, 51: 14789-14792.

DOI: $10.1039 / \mathbf{c 5 c c 0 5 8 5 0 c}$

[52] H. Li, K. Wang, Y. Sun, C.T. Lollar, J. Li, H.C. Zhou. Recent advances in gas storage and separation using metal-organic frameworks, Mater. Today. 2018, 21: 108-121.

DOI: 10.1016/j.mattod.2017.07.006

[53] P. García-Holley, B. Schweitzer, T. Islamoglu, Y. Liu, L. Lin, S. Rodriguez, M.H. Weston, J.T. Hupp, D.A. Gómez-Gualdrón, T. Yildirim, O.K. Farha. Benchmark Study of Hydrogen Storage in Metal-Organic Frameworks under Temperature and Pressure Swing Conditions. ACS Energy Lett., 2018, 3: 748-754.

DOI: 10.1021/acsenergylett.8b00154

[54] D.A. Gómez-Gualdrón, Y.J. Colón, X. Zhang, T.C. Wang, Y.S. Chen, J.T. Hupp, T. Yildirim, O.K. Farha, J. Zhang, R.Q. Snurr. Evaluating topologically diverse metal-organic frameworks for cryo-adsorbed hydrogen storage. Energy Environ. Sci., 2016.

\section{DOI: 10.1039/C6EE02104B}

[55] G. Ricchiardi, J.G. Vitillo, D. Cocina, E.N. Gribov, A. Zecchina. Direct observation and modelling of ordered hydrogen adsorption and catalyzed ortho-para conversion on ETS-10 titanosilicate material. Phys. Chem. Chem. Phys., 2007, 9: 2753-2760.

DOI: 10.1039/b703409a

[56] J.L.C. Rowsell, O.M. Yaghi. Strategies for hydrogen storage in metal-organic frameworks, Angew. Chemie Int. Ed., 2005, 44: 4670-4679.

DOI: 10.1002/anie.200462786

[57] D.P. Broom, C.J. Webb, G.S. Fanourgakis, G.E. Froudakis, P.N. Trikalitis, M. Hirscher. Concepts for improving hydrogen storage in nanoporous materials. Int. J. Hydrogen Energy, 2019, 44: 7768-7779.

DOI: 10.1016/j.jijhydene.2019.01.224

[58] A. Ahmed, S. Seth, J. Purewal, A.G. Wong-Foy, M. Veenstra, A.J. Matzger, D.J. Siegel. Exceptional hydrogen storage achieved by screening nearly half a million metal-organic frameworks. Nat. Commun., 2019, 10 .

DOI: 10.1038/s41467-019-09365-w

[59] B.J. Sikora, R. Winnegar, D.M. Proserpio, R.Q. Snurr. Textural properties of a large collection of computationally constructed MOFs and zeolites. Microporous Mesoporous Mater, 2014, 186: 207-213.

DOI: 10.1016/j.micromeso.2013.11.041 